\title{
Heat and Mass Transfer in the Adsorbent Bed of an Adsorption Heat Pump
}

\author{
HASAN DEMIR, ${ }^{1}$ MOGHTADA MOBEDI, ${ }^{2}$ AND \\ SEMRA ÜLKÜ ${ }^{1}$ \\ ${ }^{1}$ Department of Chemical Engineering, Izmir Institute of Technology, \\ Izmir, Turkey \\ ${ }^{2}$ Department of Mechanical Engineering, Izmir Institute of Technology, \\ Izmir, Turkey
}

\begin{abstract}
The heat and mass transfer equations governing an adsorbent bed in an adsorption heat pump and the mass balance equation for the adsorbent particles in the adsorbent bed were solved numerically to simulate the cycle of a basic adsorption heat pump, which includes isobaric adsorption, isosteric heating, isobaric desorption, and isosteric cooling processes. The finite difference method was used to solve the set of governing equations, which are highly nonlinear and coupled. The pressures of the evaporator and condenser were 2 and $20 \mathrm{kPa}$, respectively, and the regeneration temperature of the bed was $403 \mathrm{~K}$. Changes in the temperature, adsorptive pressure, and adsorbate concentration in the adsorbent bed at different steps of the cycle were determined. The basic simulated cycle is presented in a ClausiusClapeyron diagram, which illustrates the changes in average pressure and temperature of the adsorbent bed throughout the cycle. The results of the simulation indicated that the most time-consuming processes in the adsorption heat pump cycle were isobaric adsorption and isobaric desorption. The high thermal resistance of the bed slows down heat transfer, prolonging adsorption and desorption processes.
\end{abstract}

Keywords Adsorption heat pump; Heat and mass transfer; Silica gel

\section{Introduction}

Adsorption heat pumps (AHP) have gained a considerable amount of attention in the past two decades. Despite the many advantages of AHPs, the industrial market for adsorption heat pumps is narrow due to several important limitations. The main drawback of AHPs is their low specific heating and cooling powers (SHP/SCP), which are attributed to slow heat and mass transport in the adsorbent bed. The thermal conductivities of solid adsorbents are generally low, and the voids between granules cause discontinuities within the adsorbent bed. Moreover, the adsorption heat pump must be operated under vacuum; as a result, experimental studies are difficult and expensive. The simulation of heat and mass transport in an adsorbent bed provides information that can be used in the design of an adsorption heat pump.

Address correspondence to Moghtada Mobedi, Department of Mechanical Engineering, Izmir Institute of Technology, 35430, Izmir, Turkey. E-mail: moghtadamobedi@iyte.edu.tr 
Moreover, the results of theoretical studies can be used to optimize the parameters of an adsorbent bed and to achieve maximum specific heating and/or cooling powers (Ülkü, 1986, 1991; Demir et al., 2008).

Two types of transfer processes occur in a granular adsorbent bed, including intra-particle and interparticle heat and mass transfer. Intra-particle heat or mass transfer refers to heat or mass transport within an adsorbent particle, while interparticle heat or mass transfer is the transportation of heat or mass through the voids between particles. A survey of the literature reveals that many numerical studies have been conducted on heat and mass transfer in the adsorbent bed of an adsorption heat pump. For instance, Sakoda and Suzuki (1986) simulated heat and adsorbate transfer in the adsorbent bed of a solar-powered adsorption heat pump. Interparticle heat and mass transfer resistances were neglected, and the linear drive force (LDF) method was used to determine the concentration of the adsorbate in the adsorbent particles. By conducting a numerical study based on interparticle heat transfer resistence, Chahbani et al. (2002) determined the effects of intra-particle mass transfer kinetic models on the results of a simulated adsorption cooling machine. Ben Amar et al. (1996) investigated the effects of cycle time, permeability, and regeneration temperature on the specific cooling power of an AHP and numerically solved the coupled heat and mass transfer equations of the system by considering interparticle heat and mass transfer resistance. The effects of the operating conditions and geometrical parameters of the adsorbent bed on the performance of an adsorption heat pump were numerically investigated by Leong and Liu (Leong and Liu, 2004; Liu and Leong, 2005). In their study, the AHP was based on zeolite 13X-water pair, and the adsorbent bed was a hollow cylinder. The adsorbent particles were located between the outer and inner metal tubes of the cylinder and interparticle heat and mass transfer resistances were considered in the governing equations. Liu and Leong (2006) also simulated a novel cascade adsorption heat pump based on zeolite-water and silica gel-water pairs. Interparticle heat and mass transfer resistance in the bed was neglected, and a coefficient of performance (COP) of 1.35 and a specific cooling power of $43 \mathrm{~W} \mathrm{~kg}^{-1}$ were obtained.

Chua et al. (1999) studied the effects of switching of system and cycle time on the performance criteria of an AHP. During adsorption and desorption, the entire adsorbent bed was assumed to be at evaporator and condenser pressure, respectively; therefore, interparticle heat and mass transfer resistance were neglected. However, the thermal capacitance of the heat exchanger was taken into account. Freni et al. (2008) and Maggio et al. (2009) simulated solar-powered adsorptive ice makers and solved a time-dependent heat transfer equation for the adsorbent bed. Restuccia et al. (2004) performed numerical and experimental studies on a selective water adsorbent used in a solid adsorption chiller. The heat and mass balance equations for the adsorbent bed were solved by neglecting interparticle heat and mass transfer resistances in the bed. Demir et al. (2009) studied the effects of porosity on heat and mass transfer in a granular adsorbent bed during the adsorption process. The heat and mass transfer equations of the annular adsorbent bed were solved numerically, and the LDF method was used to determine the concentration of the adsorbate in the adsorbent particle. Moreover, changes in the temperature and adsorbate concentration in the bed were determined throughout the adsorption process.

The adsorption and desorption periods of an adsorption heat pump can be specified according to the application of the heat pump. For some applications, such 
as the air conditioning in a vehicle, adsorption and desorption periods must be less than $30 \mathrm{~min}$. Alternatively, to utilize solar energy during the regeneration process, the adsorption/desorption period of a solar-powered refrigerator must be greater than $8 \mathrm{~h}$. In industrial applications where the adsorbent bed is located in a chimney, the desired adsorption/desorption period may be longer than one day. In the present study, an adsorbent bed designed for a long-term cycle was studied.

A survey of the literature revealed that the majority of studies focused on the effects of operational and/or geometrical parameters of the adsorbent bed on the performance criteria of an AHP. However, to develop methods of accelerating heat and mass transfer within the bed, detailed studies on the effects of various parameters on the mechanism of heat and mass transfer in the adsorbent bed should be investigated. In the present study, the mechanism of heat and mass transfer in a granular-type adsorbent bed was analyzed during the four processes of an AHP cycle. A basic cycle of an adsorption heat pump is considered in the present study. The governing equations, including heat and mass transfer equations for the adsorbent bed and mass balance equations for the adsorbent granules, are presented. Moreover, the cycle is depicted in a Clausius-Clapeyron diagram.

\section{The Cycle of an Adsorption Heat Pump}

The cycle of an adsorption heat pump consists of four processes: isosteric heating (a-b), isobaric desorption (b-c), isosteric cooling (c-d), and isobaric adsorption (d-a), as shown in Figure 1. In the AHP cycle, cooling effects occur during isobaric adsorption (d-a) due to adsorbate evaporation, which is caused by the influx of heat from the environment. Alternatively, heating effects occur during isobaric desorption (b-c) due to the condensation of the adsorbate, which is caused by the release of heat to the surroundings. Moreover, heat transferred to the surroundings during isosteric cooling and isobaric adsorption can also be utilized during the cycle. In the isosteric heating process ( $a-b)$, the adsorbent bed is heated at a constant adsorbate concentration, and the pressure of the bed increases from evaporator to condenser pressure. During isosteric cooling (c-d), the adsorbent bed is cooled to reduce the pressure and temperature of the adsorbent bed at a constant adsorbate concentration (Demir et al., 2008).
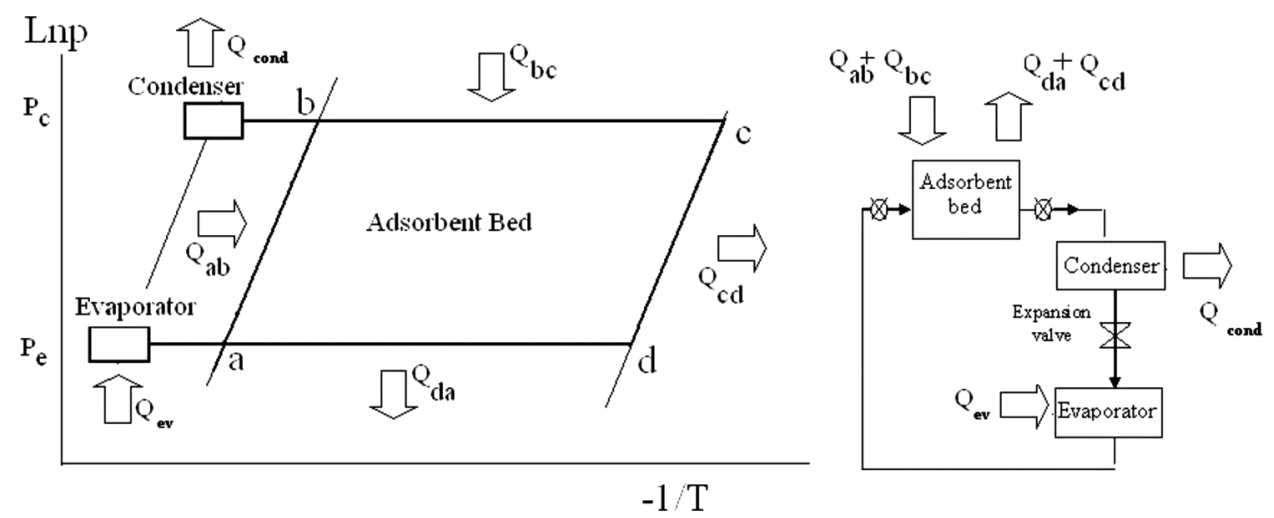

Figure 1. Thermodynamic cycle of a basic adsorption heat pump. 


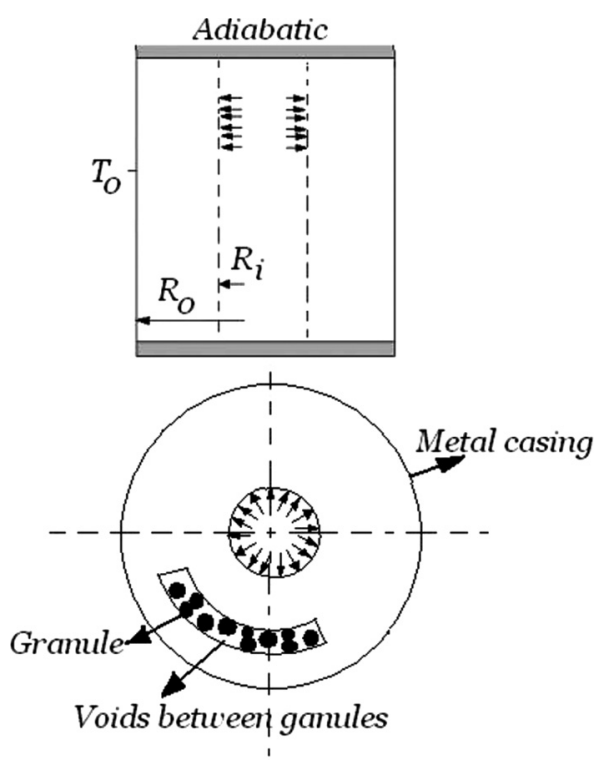

Figure 2. Schematic view of the adsorbent bed.

\section{The Annular Adsorbent Bed}

The adsorbent bed considered in this study is shown in Figure 2. The adsorbent granules consist of silica gel grains, and water was used as the adsorbate. The upper and lower surfaces of the adsorbent bed were insulated, and it was assumed that the transfer of heat and mass occurred only in the radial direction. The adsorptive could easily flow through the center of the annulus into the adsorbent bed at a uniform velocity. The adsorptive (i.e., water vapor) flowed from the surface of the inlet $\left(\mathrm{R}=\mathrm{R}_{\mathrm{i}}\right)$ towards the outer surface of the bed $\left(\mathrm{R}=\mathrm{R}_{\mathrm{o}}\right)$. The thermal resistance of the metal casing of the adsorbent bed was neglected in the numerical analyses. The inner and outer radii of the annular adsorbent bed were 0.06 and $0.16 \mathrm{~m}$, respectively, and the equivalent radius of the adsorbent granule was $0.0016 \mathrm{~m}$.

\section{Governing Equations}

Mass transfer in a granular adsorbent bed occurs within the adsorbent particle and in the voids between the granules (i.e., intra-particle and interparticle mass transfer). The mechanism of heat and mass transfer in a granular adsorbent bed is complicated; hence, some assumptions must be made in order to establish the governing equations. The assumptions made in this study are (1) the size of the adsorbent granules were uniform; thus, the porosity of the bed was constant; (2) the adsorbed water was in the liquid phase and the adsorptive behaved as an ideal gas; (3) the thermal resistance of the adsorbent granules was negligible; (4) the temperature of the adsorbent granule was equal to the temperature of the surrounding adsorptive; (5) the thermal properties of the adsorbent particles and the adsorbate were constant; and (6) the rate of heat transfer at the adsorptive inlet surface, $R=R_{i}$, was negligible. 
Based on the above assumptions, the governing equations of the adsorbent bed were written as:

$$
\begin{gathered}
\left(\left(\rho C_{p}\right)_{e f f}+\rho_{s} C_{p w} W\right) \frac{\partial T}{\partial t}=\lambda_{e f f} \frac{1}{R} \frac{\partial}{\partial R}\left(R \frac{\partial T}{\partial R}\right)-\frac{1}{R} \frac{\partial}{\partial R}\left(\rho_{w} C_{p w} R u T\right)+\rho_{s} \Delta H_{s t} \frac{\partial W}{\partial t} \\
\frac{\partial \rho_{w}}{\partial t}+\left(\frac{1}{\varepsilon}\right) \rho_{s} \frac{\partial W}{\partial t}+\frac{1}{\varepsilon R} \frac{\partial}{\partial R}\left(R \rho_{w} u\right)=0 \\
\frac{\partial W}{\partial t}=\frac{15 D_{e f f}}{R_{p}^{2}}\left(W_{\infty}-W\right)
\end{gathered}
$$

Equations (1) and (2) are the heat and mass transfer equations of the adsorbent bed. As shown in the equations, heat and mass were transferred in the radial direction of the bed, and the effect of the adsorption rate within the granule was taken into account by $\partial W / \partial t$. Equation (3) is the mass balance equation for the adsorbent granule. The distribution of adsorptive pressure in the bed can be obtained from the distribution of the adsorptive density by the ideal gas law. By applying the ideal gas law to Darcy's law, the following equation used to determine the velocity field of the adsorptive:

$$
u=-K_{a p p} \frac{R}{M \mu} \frac{\partial\left(\rho_{w} T_{w}\right)}{\partial R}
$$

The apparent permeability of the adsorbent bed, $\mathrm{K}_{\mathrm{app}}$, can be calculated from the following expression (Leong and Liu, 2004):

$$
K_{a p p}=K+\frac{\varepsilon \mu}{\tau P} D_{b e d}
$$

where $\mathrm{K}$ is the inherent permeability of the adsorbent bed and can be obtained from the Blake-Kozeny equation, which is valid for void fractions less than $\varepsilon=0.5$ (Bird et al., 2002). The Blake-Kozeny equation can be used to determine the permeability of a packed column with laminar flow. The present adsorbent bed was considered to be a packed bed through which water vapor flows due to adsorption and desorption to/from the adsorbent particle. Therefore, the Blake-Kozeny equation can be used to determine the permeability of the analyzed adsorbent bed.

$$
K=\frac{R_{p}^{2} \varepsilon^{3}}{37.5(1-\varepsilon)^{2}}
$$

In Equation (5), $\mathrm{D}_{\text {bed }}$ was derived from the two mechanisms of adsorptive diffusion in the adsorbent bed: Knudsen diffusion and molecular diffusion. The value of $\mathrm{D}_{\text {bed }}$ can be obtained from the following equations (Kärger and Ruthven, 1992; Leong and Liu, 2004):

$$
\frac{1}{D_{b e d}}=\frac{1}{D_{m}}+\frac{1}{D_{K}}
$$




$$
\begin{gathered}
D_{K}=97 r_{p} \sqrt{T / M} \\
D_{m}=0.02628 \frac{\sqrt{T^{3} / M}}{P \sigma^{2} \Omega}
\end{gathered}
$$

The pore radius $\left(\mathrm{r}_{\mathrm{p}}\right)$ of uniform spherical particles in a packed bed can be obtained from Equation (10) (De Nevers, 1991):

$$
r_{p}=\frac{2 R_{p}}{3} \frac{\varepsilon}{(1-\varepsilon)}
$$

In Equation (3), $\mathrm{W}_{\infty}$ is the equilibrium concentration of the adsorbate and can be determined from the following equation (Cho et al., 1992):

$$
W_{\infty}=W_{0}\left(\frac{P}{P_{\text {sat }}}\right)^{1 / n}
$$

\begin{tabular}{|c|c|c|}
\hline Parameter & Symbol & Value \\
\hline Molecular weight of water, $\mathrm{kg} \mathrm{mol}^{-1}$ & $\mathrm{M}$ & 18 \\
\hline Density of adsorbent, $\mathrm{kg} \mathrm{m}^{-3}$ & $\rho_{\mathrm{s}}$ & 670 \\
\hline Specific heats of adsorbent, $\mathrm{kJkg}^{-1} \mathrm{~K}^{-1}$ & $\mathrm{Cp}_{\mathrm{s}}$ & 0.88 \\
\hline Specific heats of adsorptive at $303 \mathrm{~K}, \mathrm{kJkg}^{-1} \mathrm{~K}^{-1}$ & $C p_{w}$ & 4.178 \\
\hline Specific heats of adsorptive at $330 \mathrm{~K}, \mathrm{kJkg}^{-1} \mathrm{~K}^{-1}$ & $C \mathrm{p}_{\mathrm{w}}$ & 4.184 \\
\hline Specific heats of adsorptive at $373 \mathrm{~K}, \mathrm{kJkg}^{-1} \mathrm{~K}^{-1}$ & $C \mathrm{p}_{\mathrm{w}}$ & 4.217 \\
\hline Specific heats of adsorptive at $360 \mathrm{~K}, \mathrm{kJkg}^{-1} \mathrm{~K}^{-1}$ & $C p_{w}$ & 4.203 \\
\hline Specific heats of adsorptive at $303 \mathrm{~K}, \mathrm{kJkg}^{-1} \mathrm{~K}^{-1}$ & $\mathrm{Cp}_{\mathrm{v}}$ & 1.895 \\
\hline Specific heats of adsorptive at $330 \mathrm{~K}, \mathrm{kJkg}^{-1} \mathrm{~K}^{-1}$ & $\mathrm{Cp}_{\mathrm{v}}$ & 1.911 \\
\hline Specific heats of adsorptive at $373 \mathrm{~K}, \mathrm{kJkg}^{-1} \mathrm{~K}^{-1}$ & $\mathrm{Cp}_{\mathrm{v}}$ & 2.029 \\
\hline Specific heats of adsorptive at $360 \mathrm{~K}, \mathrm{kJkg}^{-1} \mathrm{~K}^{-1}$ & $\mathrm{Cp}_{\mathrm{v}}$ & 1.983 \\
\hline Thermal conductivity of adsorbent, $\mathrm{kW} \mathrm{m}^{-1} \mathrm{~K}^{-1}$ & $\lambda_{\mathrm{s}}$ & $0.198 \times 10^{-3}$ \\
\hline Thermal conductivity of adsorptive, $\mathrm{kW} \mathrm{m}^{-1} \mathrm{~K}^{-1}$ & $\lambda_{\mathrm{w}}$ & $1.96 \times 10^{-5}$ \\
\hline Heat of adsorption for water on silica gel, $\mathrm{kJkg}^{-1}$ & $\Delta \mathrm{H}_{\mathrm{s}}$ & 2560 \\
\hline Limiting adsorption capacity of adsorbent, $\mathrm{kg}_{\mathrm{w}} \mathrm{kg}_{\mathrm{s}}^{-1}$ & $\mathrm{~W}_{0}$ & 0.552 \\
\hline Linear driving force relationship constant & $\mathrm{n}$ & 1.6 \\
\hline Reference diffusivity, $\mathrm{m}^{2} \mathrm{~s}^{-1}$ & $\mathrm{D}_{0}$ & $2.54 \times 10^{-4}$ \\
\hline Diffusion activation energy, $\mathrm{J} \mathrm{mol}^{-1}$ & $\mathrm{E}$ & $4.2 \times 10^{4}$ \\
\hline Collision diameter for Lennard-Jones potential, A & $\sigma$ & 2.641 \\
\hline Collision integral & $\Omega$ & 2.236 \\
\hline Boltzmann's constant $\left(\mathrm{J} \mathrm{K}^{-1}\right.$ molecule $\left.^{-1}\right)$ & $\mathrm{k}$ & $1.38 \times 10^{-23}$ \\
\hline Tortuosity & $\tau$ & 3 \\
\hline Viscosity of water vapor, $\mathrm{kNsm}^{-2}$ at $303 \mathrm{~K}$ & $\mu$ & $9.09 \times 10^{-9}$ \\
\hline Viscosity of water vapor, $\mathrm{kNsm}^{-2}$ at $330 \mathrm{~K}$ & $\mu$ & $10.29 \times 10^{-9}$ \\
\hline Viscosity of water vapor, $\mathrm{kNsm}^{-2}$ at $373 \mathrm{~K}$ & $\mu$ & $12.02 \times 10^{-9}$ \\
\hline Viscosity of water vapor, $\mathrm{kNsm}^{-2}$ at $360 \mathrm{~K}$ & $\mu$ & $11.49 \times 10^{-9}$ \\
\hline
\end{tabular}

Table I. Thermophysical properties of adsorbent granule and adsorbate considered in the present study (Ben Amar et al., 1996; Restuccia et al., 2002; Cussler, 1997) 


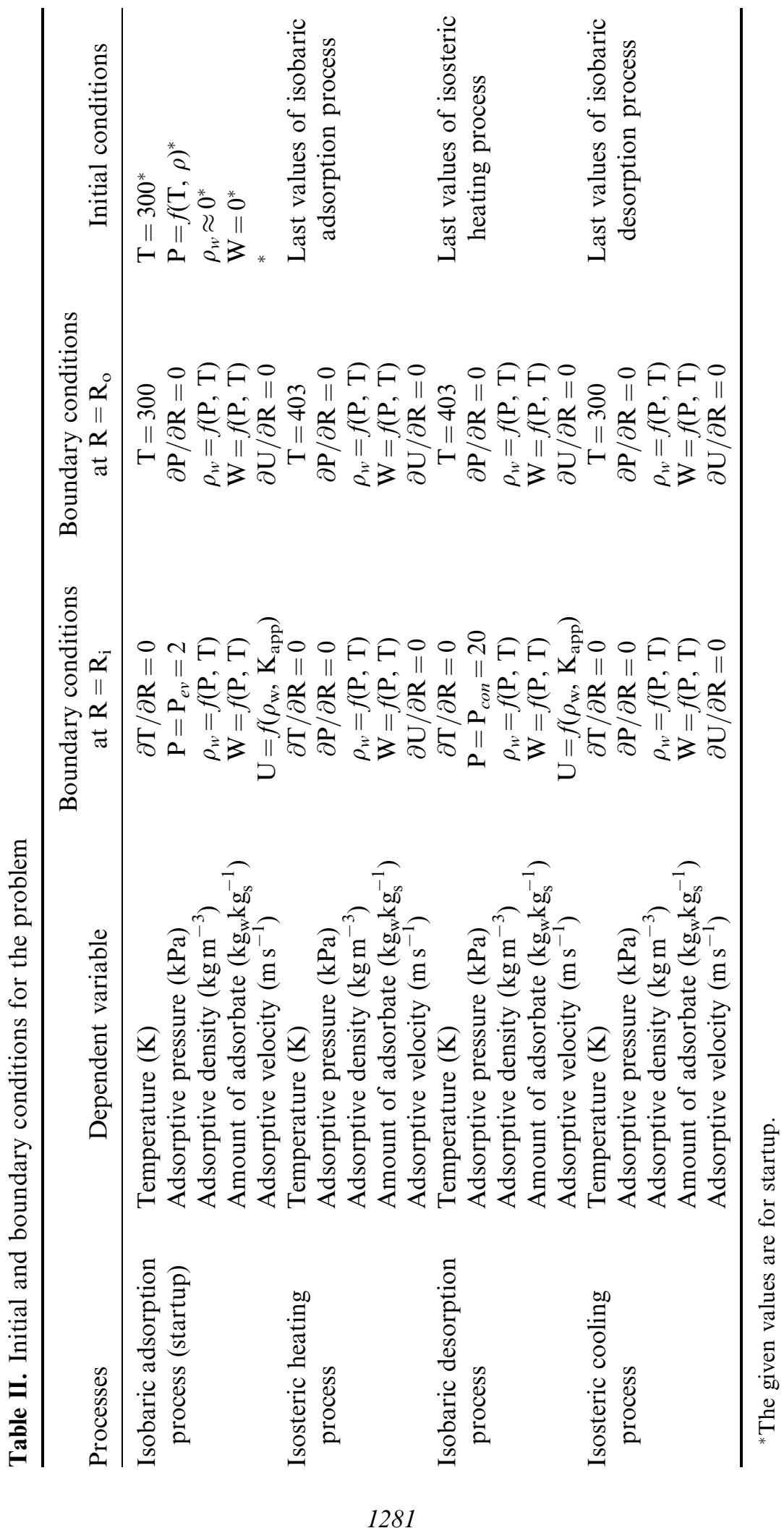


where $\mathrm{n}$ is the linear driving relationship constant (Table I). The effective mass transfer diffusivity of the adsorbent particle is temperature dependent and can be calculated from the Arrhenius equation (Ben Amar et al., 1996):

$$
D_{\text {eff }}=D_{o} e^{-E / R T}
$$

The effective thermal conductivity and the effective thermal capacitance of the bed, $\left(\rho \mathrm{C}_{\mathrm{p}}\right)_{\text {eff }}$, can be obtained from the following expressions (Tavman and Akinci, 2000; Incropera and DeWitt, 1996):

$$
\begin{gathered}
\lambda_{e f f}=\lambda_{s}^{(1-\varepsilon)} \lambda_{w}^{\varepsilon} \\
\left(\rho C_{p}\right)_{e f f}=\varepsilon\left(\rho C_{p}\right)_{v}+\left(\rho C_{p}\right)_{s}
\end{gathered}
$$

The thermophysical properties of silica gel and water are provided in Table I (Ben Amar et al., 1996; Restuccia et al., 2002; Cussler, 1997).

As previously mentioned, the cycle of an adsorption heat pump involves four processes, namely isobaric adsorption, isosteric heating, isobaric desorption, and isosteric cooling. The initial and boundary conditions for each process are presented in Table II. The cycle begins with isobaric adsorption and continues onto the next process. The final values of the dependent variables at the end of each process are the initial conditions for the following process. The outer surface of the adsorbent bed was maintained at $300 \mathrm{~K}$ during isobaric adsorption and isosteric cooling, and the temperature of the outer surface of the bed increased to $403 \mathrm{~K}$ during isosteric heating and isobaric desorption. The pressure of the adsorptive was 2.0 and $20 \mathrm{kPa}$ at the inner surface of the annulus (i.e., $\mathrm{R}=\mathrm{R}_{\mathrm{i}}$ ) during adsorption and desorption, respectively.

\section{Solution Procedure}

The set of equations governing the four processes in the adsorbent bed are highly nonlinear and coupled. Furthermore, the mass transfer diffusivity of the adsorbent particles and the apparent permeability of the adsorbent bed are functions of the temperature and pressure of the system. To solve the governing equations, the equations were discretized in time and the radial direction of the bed. The finite difference forms of the convection and diffusion terms were written based on the central difference scheme, and an implicit method was applied. The energy equation (Equation (1)) was solved to determine the temperature field in the adsorbent bed. Based on the temperature field, the mass transfer equation (Equation (2)) for the adsorbent bed was solved to determine the distribution of the adsorptive density. The pressure field and velocity distribution in the bed were calculated by applying the values of the adsorptive density. The first-order differential equation of the LDF method was solved to determine the changes in the adsorbate concentration in the particle. Before the time step was increased, an inner iteration was performed until the following convergence criterion was satisfied:

$$
\left|\frac{\left(\varphi^{n+1}-\varphi^{n}\right)}{\varphi^{n} \cdot \Delta t}\right|_{\max }<10^{-4}
$$


where $\mathrm{n}$ is a step of the inner iteration and $\varphi$ is the temperature and adsorptive density. The distribution of the grid was uniform, and 10 grids were employed. The computer code was written in FORTRAN. The following equation was used to determine the average value of the dependent variables $\left(\mathrm{T}, \mathrm{P}, \rho_{\mathrm{w}}, \mathrm{W}\right)$ in the bed:

$$
\bar{\varphi}(t)=\frac{\int_{R_{i}}^{R_{o}} 2 R \varphi(R, t) d R}{\left(R_{o}^{2}-R_{i}^{2}\right)}
$$

\section{Results and Discussion}

Under the initial and boundary conditions provided in Table II, the equations governing the cycle were solved. The average pressure and temperature of the adsorbent bed were obtained and plotted in a Clausius-Clapeyron diagram to illustrate the processes that make up the cycle (Figure 3). The dashed line shows the ideal cycle, and the continuous line represents the basic cycle obtained from numerical results. Cycle 1 , which was different from cycles 2 and 3, was the startup cycle. The main difference between cycle 1 and cycles 2 and 3 was observed during isobaric adsorption. The isosteric heating, isosteric cooling, and isobaric desorption processes in cycle 1 were identical to those of cycles 2 and 3 . The differences between the adsorption process of cycle 1 and cycles 2 and 3 was due to the initial conditions. The adsorbent bed was assumed to be completely dry (i.e., $\mathrm{W}=0$ ), and the pressure, temperature, and adsorbate concentration in the bed were uniform at the beginning of the startup cycle. The heat of adsorption at low concentrations of adsorbate was high, which increased the temperature of the adsorbent bed. Therefore, the average temperature of the adsorbent bed reached $373 \mathrm{~K}$ during the isobaric adsorption process of the startup cycle. The results of the adsorption process of cycle 2 (d-a process) were obtained by applying the final values of isosteric cooling in cycle 1 , and the procedure was continued through cycle 3. As shown in Figure 3, cycles 2 and 3 were identical; thus, cycle 3 is the permanent cycle, and further cycles would be identical to cycle 3 . Hence, all discussions in the present study are based on the results of cycle 3. As shown in Figure 3(c), the adsorption process was completely isobaric, and the pressure was maintained at $2 \mathrm{kPa}$. The average adsorbate concentration in the adsorbent bed increased from $11.5 \%$ to $30 \%$. During isosteric heating, the adsorbate concentration was constant, and the adsorbent pressure increased from 2 to $20 \mathrm{kPa}$, which are the pressures of the evaporator and condenser, respectively. The isobaric desorption process nearly overlapped the ideal process, as shown in Figure 3(c). A small deviation from the ideal cycle was observed during isosteric cooling due to the sudden change in the surface temperature of the bed from 403 to $300 \mathrm{~K}$. This deviation can be eliminated by increasing the number of grids and reducing the numerical errors.

The temperature distribution along the radius of the annular bed during the four processes of the cycle is shown in Figure 4. During adsorption (Figure 4(a)) the temperature of the outer surface of the adsorbent bed was $300 \mathrm{~K}$, and the temperature of the adsorbent medium was higher than the surface temperature at the beginning of the adsorption process. The temperature of the adsorbent decreased over time; however, the temperature of the inner region decreased slowly due to the low thermal conductivity of the adsorbent bed. After approximately $6 \mathrm{~h}$, the temperature of the 


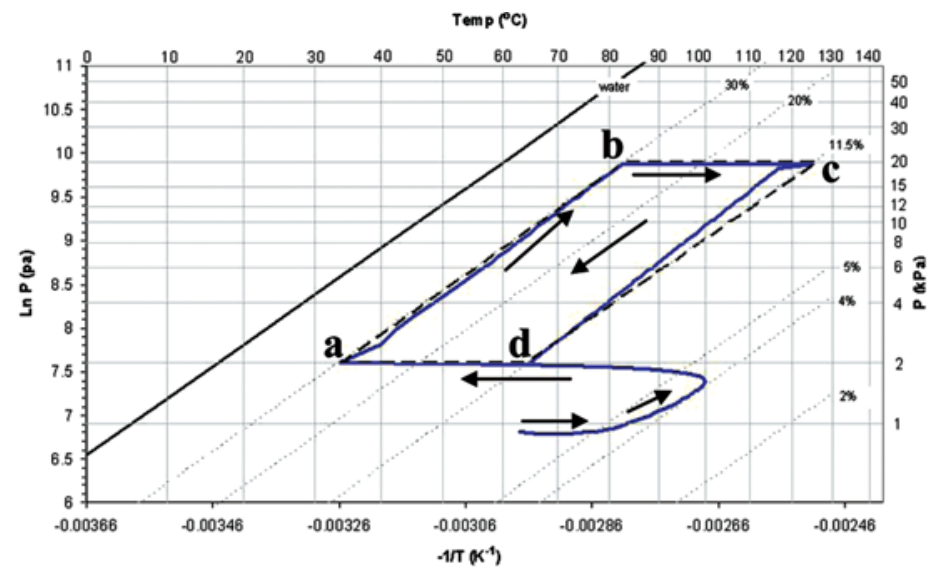

(a)

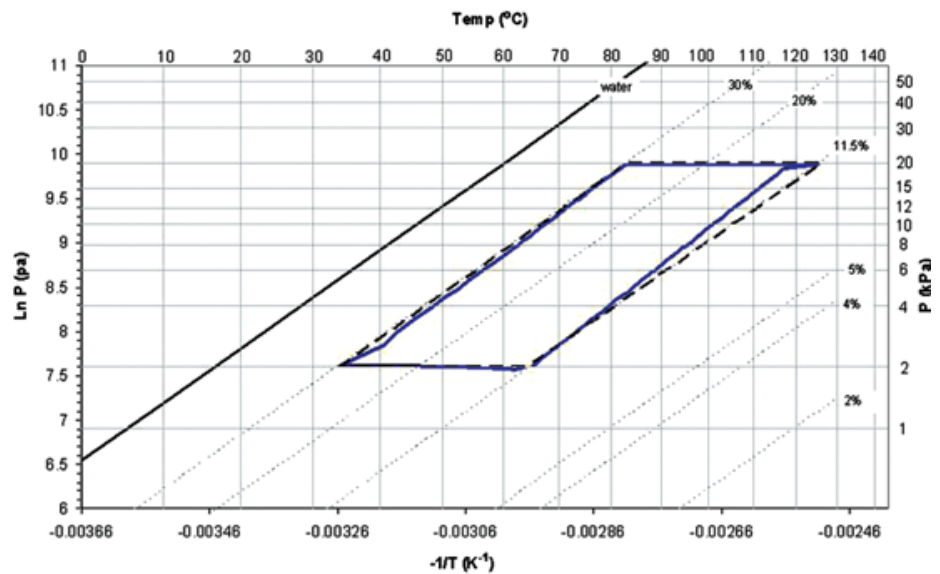

(b)

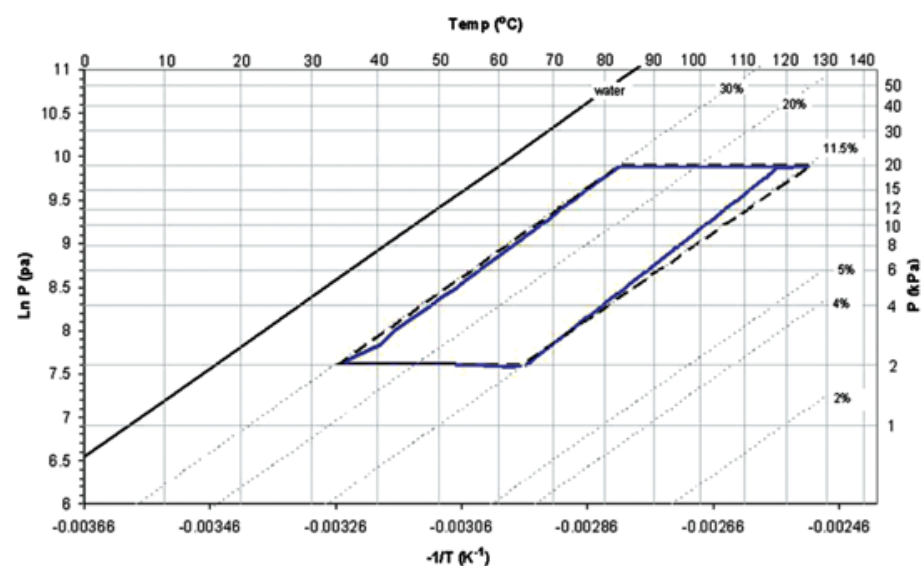

(c)

Figure 3. LnP vs. -1/T diagram of the simulated cycle; (a) startup cycle, (b) cycle 2, (c) cycle 3. 


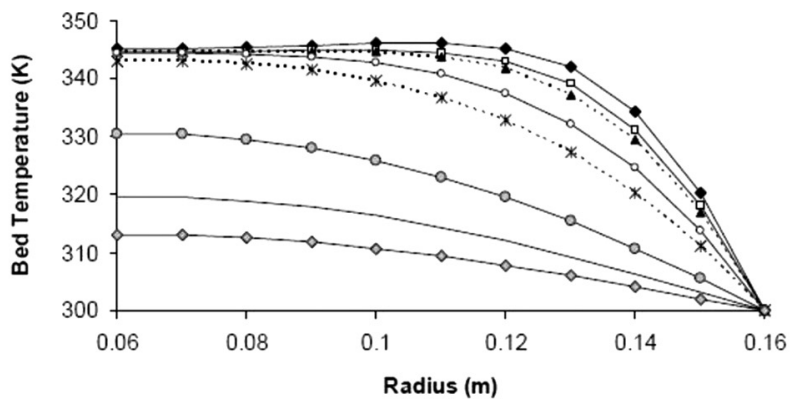

$$
\begin{array}{|l|}
\longrightarrow-5 \min \\
-\square-30 \mathrm{~min} \\
\cdots \cdots 1 \mathrm{~h} \\
\multimap-3 \mathrm{~h} \\
\cdots * \cdots 6 \mathrm{~h} \\
\multimap-24 \\
-50 \\
\multimap-80 \mathrm{~h} \\
\hline
\end{array}
$$

(a)
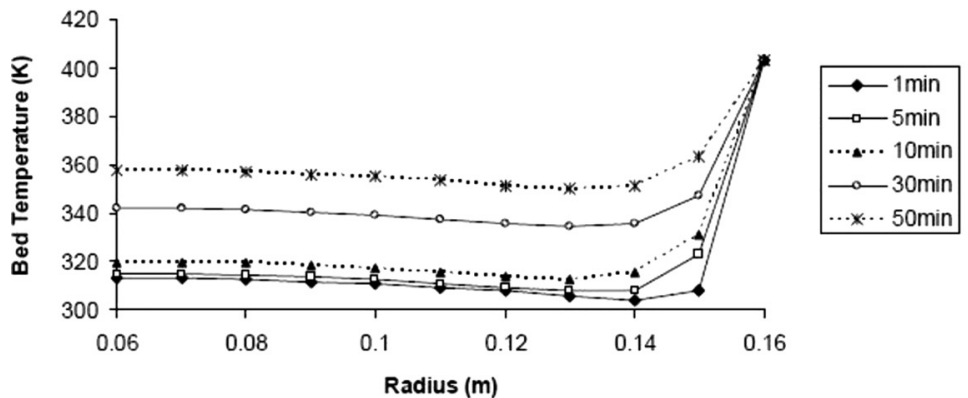

(b)
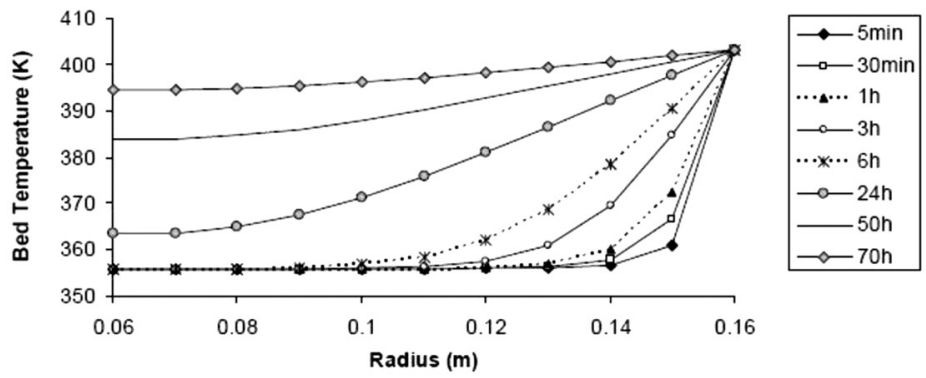

(c)
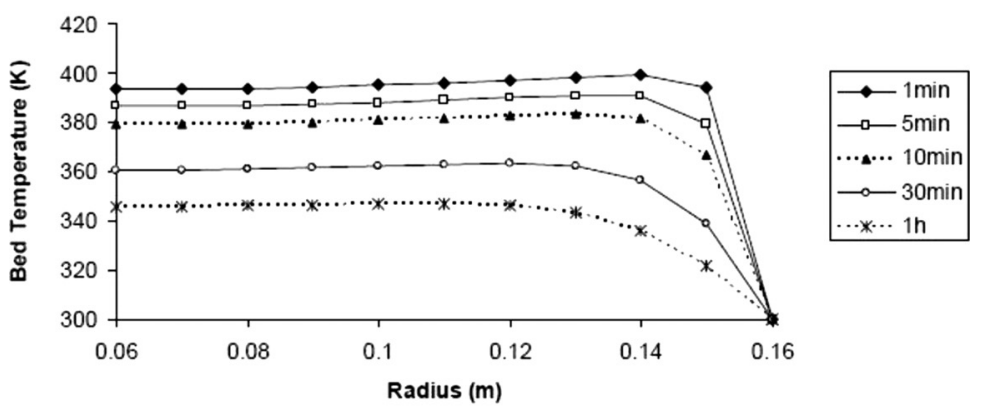

(d)

Figure 4. Variation in bed temperature along the radius of adsorbent bed; (a) isobaric adsorption, (b) isosteric heating, (c) isobaric desorption, (d) isosteric cooling. 
inner surface of the annulus (i.e., $\mathrm{R}=\mathrm{R}_{\mathrm{i}}$ ) began to decrease. The generation of heat during the adsorption process is another factor that reduces the cooling rate of the adsorbent bed. The average temperature of the bed decreased to $307 \mathrm{~K}$ after $80 \mathrm{~h}$.

As shown in Figure 4(b), the temperature of the outer surface of the adsorbent bed was set to $403 \mathrm{~K}$ during the isosteric heating process. A steep temperature gradient was observed in the region next to the outer surface of the bed due to the sudden change in the surface temperature. The temperature of the bed increased over time and reached $360 \mathrm{~K}$ after one hour. Moreover, uniform temperature distribution was observed in most regions of the adsorbent bed during isosteric heating. During the isobaric desorption process, which is illustrated in Figure 4(c), the outer surface of the adsorbent bed was maintained at the same temperature as the isosteric heating process (i.e., $403 \mathrm{~K}$ ). The temperature of the outer region of the annulus bed increased rapidly; however, the temperature change in the inner region of the bed was slower due to the poor thermal diffusivity of the adsorbent bed. A portion of the heat transferred from the outer surface of the annulus to the adsorbent bed was consumed by the desorption of the adsorbate from the adsorbent particles. The temperature of the adsorbent bed reached the temperature corresponding to point $\mathrm{c}$ of Figure 3(a) in $70 \mathrm{~h}$. The temperature distribution in the bed during the isosteric cooling process is shown in Figure 4(d). Similar to the isosteric heating process, the temperature in most regions of the adsorbent bed was uniform, and the process was complete in a short period of time. After one hour, the average temperature of the adsorbent bed fell to a temperature of $T_{d}$. As shown in Figure 4, the final temperature distribution of one process is the initial temperature condition of the next process.

The distribution of the adsorbate concentration along the radius of the bed during the four processes of the cycle is shown in Figure 5. Changes in the adsorbate concentration in the adsorbent bed during the adsorption process are illustrated in Figure 5(a). In the region adjacent to the outer surface of the bed, where the temperature was relatively low, the concentration of the adsorbate was high. The adsorbate concentration was high in adsorbent particles located in other lowtemperature regions. During the adsorption process, the average concentration of the adsorbate in the bed was $30 \%$ after $80 \mathrm{~h}$. Figure 5 (a) indicates the importance of heat transfer in the bed. As shown in the figure, the adsorbate concentration in the bed was strongly influenced by the adsorbent temperature. For instance, the adsorbate concentration in the inner region of the annulus increased with a decrease in the adsorbent temperature. Hence, the thermal resistance of the adsorbent bed controls heat and mass transport in the adsorbent bed.

As shown in Figure 5(b) the average adsorbate concentration during the isosteric heating process remained constant. The adsorbate concentration in the outer region of the adsorbent bed was low due to the desorption of the adsorbate at high temperatures.

The local change in the adsorbate concentration during the isobaric desorption process is presented in Figure 5(c). The results indicated that the adsorbate concentration in the inner region of the adsorbent bed remained constant during the first $6 \mathrm{~h}$ of the isobaric desorption process because the poor effective thermal conductivity of the bed reduced the transfer of heat to the inner region of the adsorbent bed. Furthermore, a portion of the heat transferred to the adsorbent bed was consumed by desorption of water from the adsorbent particles. Thus, the adsorbate concentration decreased from 0.300 to $0.115 \mathrm{~kg}_{\mathrm{w}} \mathrm{kg}_{\mathrm{s}}^{-1}$ within $70 \mathrm{~h}$. Figure $5(\mathrm{~d})$ illustrates 


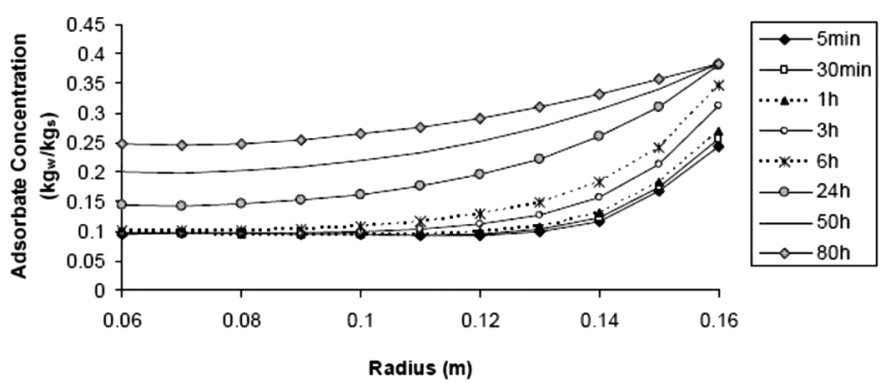

(a)

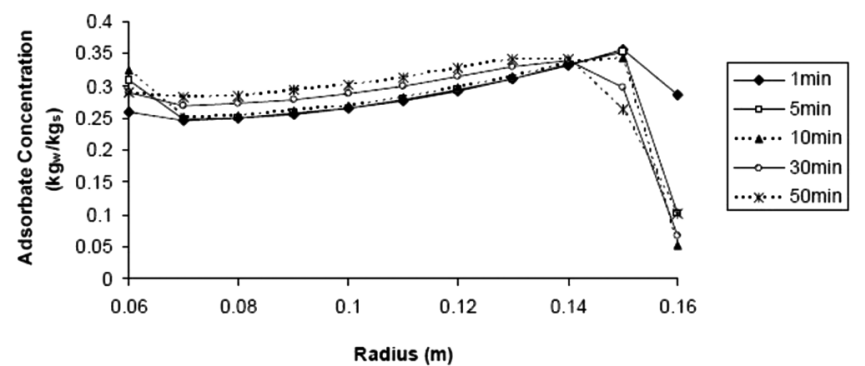

(b)

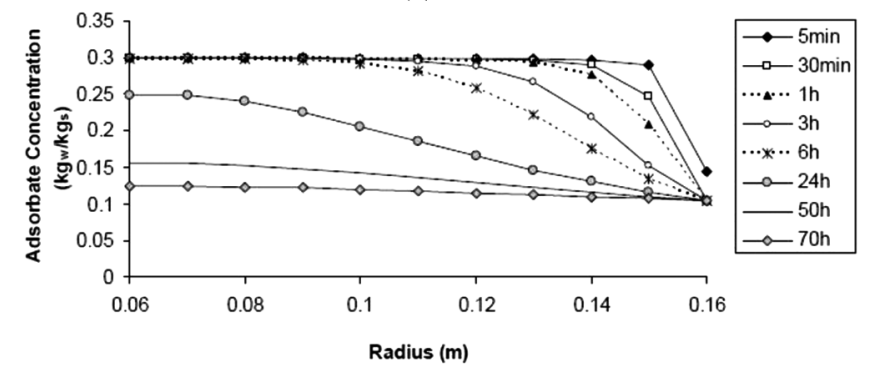

(c)

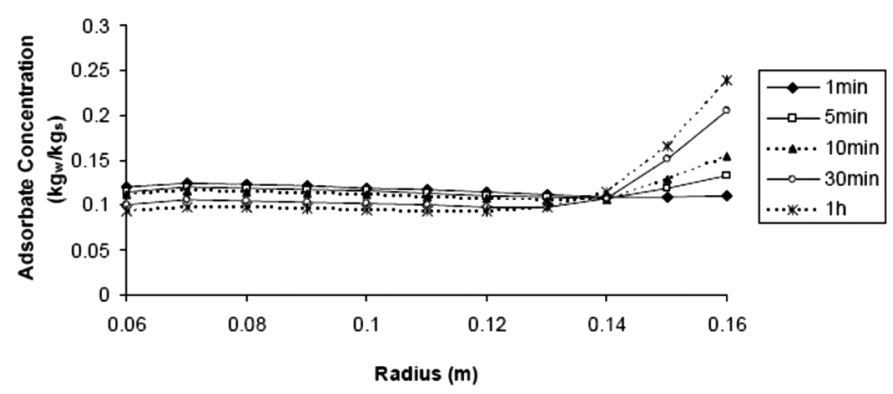

(d)

Figure 5. Variation in adsorbate concentration along the radius of adsorbent bed; (a) isobaric adsorption, (b) isosteric heating, (c) isobaric desorption, (d) isosteric cooling.

the distribution of the adsorbate concentration in the adsorbent bed during the isosteric cooling process. During isosteric cooling, the adsorbate concentration in the bed is relatively low, and the average adsorbate concentration remained constant. Changes in the adsorbate concentration were not observed because $\partial \mathrm{P} / \partial \mathrm{R}=0$ at 
the inner and outer surfaces of the annulus, and the adsorptive cannot flow to/from the boundaries of the bed.

The variation in the adsorptive pressure of the bed throughout all four processes of cycle 3 is shown in Figure 6. The local variation in the adsorptive pressure of the adsorbent bed during the adsorption process is illustrated in Figure 6(a). As previously mentioned, the adsorption process is isobaric; however, for adsorptive transfer to occur, a small pressure gradient in the radial direction of the bed should exist. During the adsorption process, the pressure of the adsorptive at the inner surface of the annulus $\left(\mathrm{R}=\mathrm{R}_{\mathrm{i}}\right)$ remained constant at a pressure of $2.045 \mathrm{kPa}$. A sudden decrease in the temperature of the outer surface of the bed at the beginning of the adsorption process caused a rapid decrease in the pressure of the outer region of the bed. After one hour, the pressure gradient in the adsorbent bed disappeared, and the adsorptive pressure in the entire region of the adsorbent bed reached evaporator pressure. During isosteric heating and cooling processes (Figures 6(b) and (d)), a uniform pressure distribution was observed because the adsorbate concentration was constant and adsorptive flow to/from the boundaries of the adsorbent bed did not occur. The pressure of the bed gradually increased with the increase in the temperature of the bed during isosteric heating. Similarly, during isosteric cooling, the pressure of the bed gradually decreased as the temperature of the bed decreased. Figure 6(c) illustrates the pressure distribution in the adsorber during the isobaric desorption process. The pressure in the outer region of the annular adsorber was greater than the temperature of the inner region, causing the flow of adsorptive from the outer to the inner region of the bed. After $6 \mathrm{~h}$, the pressure gradient in the adsorbent bed decreased considerably. Although the process was isobaric, a small pressure gradient along the radius of the adsorbent bed was observed, causing the flow of adsorptive from the outer region to the inner region of the bed.

Figure 7 shows the variation in the average temperature of the adsorber throughout the cycle. The dashed line indicates the temperature of the outer surface of the bed, and the continuous line refers to the average temperature of the adsorber. In the AHP cycle, isosteric heating and cooling processes were relatively short (approximately one hour); as a result, these processes are shown as a vertical line in the graph. The temperature of the outer surface of the adsorber was $300 \mathrm{~K}$ during isobaric adsorption and isosteric cooling processes, and it was maintained at $403 \mathrm{~K}$ during isobaric desorption and isosteric heating. The average temperature of the bed was approximately $340 \mathrm{~K}$ at the beginning of the adsorption process, gradually decreasing over time to $307 \mathrm{~K}$. After $80 \mathrm{~h}$, the average temperature of the bed decreased to the temperature corresponding to point "a" in Figure 1. The average temperature of the bed increased to $360 \mathrm{~K}$ during the isosteric heating process and then increased to $400 \mathrm{~K}$ during isobaric desorption. As shown in Figure 7, the majority of the cycle consisted of isobaric adsorption and desorption processes due to the low thermal conductivity of the adsorbent bed.

The variation in the average adsorbate concentration in the adsorbent bed throughout the cycle is illustrated in Figure 8. The adsorbate concentration increased from 0.115 to $0.300 \mathrm{~kg}_{\mathrm{w}} \mathrm{kg}_{\mathrm{s}}^{-1}$ during isobaric adsorption and remained constant during isosteric heating. In the isobaric desorption process, water was desorbed from the adsorbent particles due to the heating of the adsorbent bed, and the average adsorbate concentration was reduced to $0.115 \mathrm{~kg}_{\mathrm{w}} \mathrm{kg}_{\mathrm{s}}^{-1}$.

Figure 9 illustrates the change in the average bed pressure over time during the four processes of the cycle. As expected, the average bed pressure remained constant 


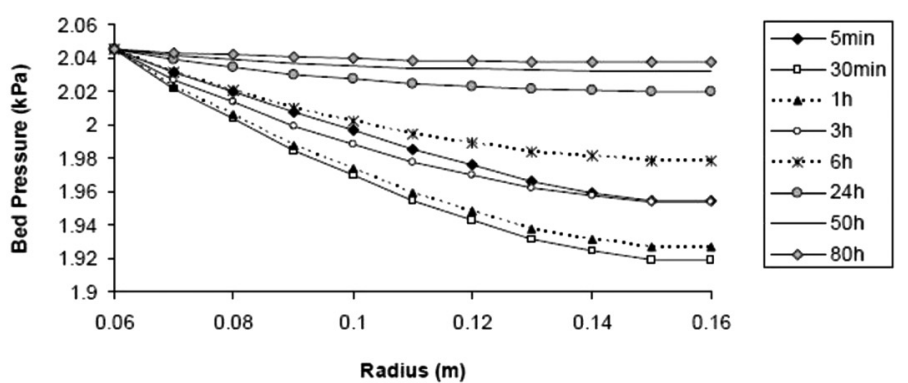

(a)

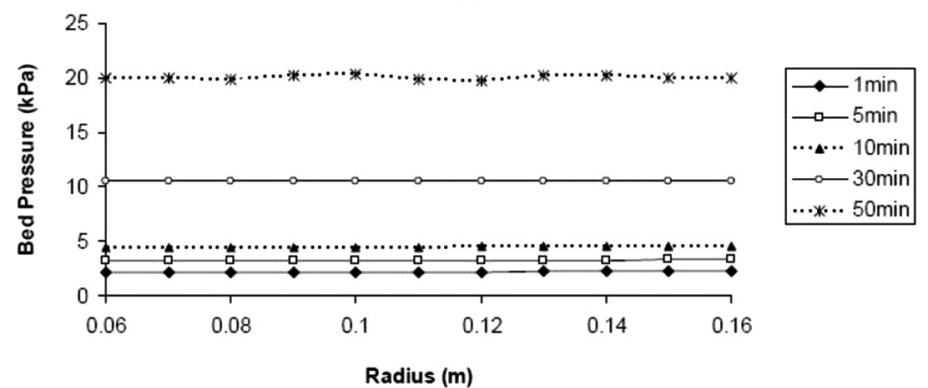

(b)

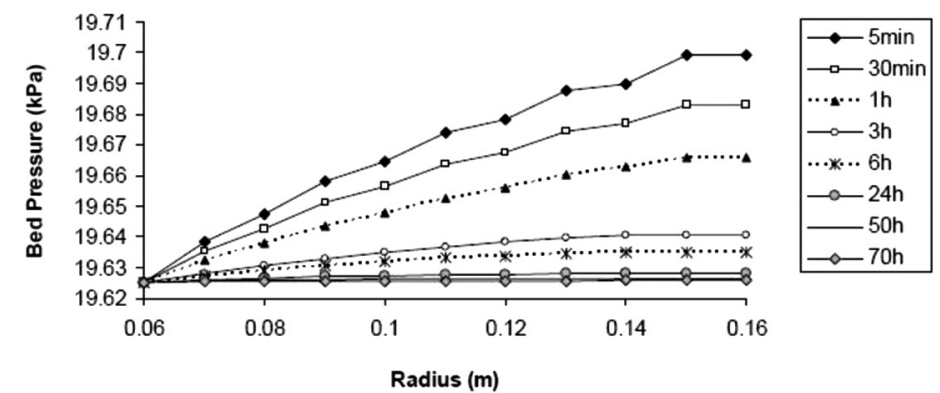

(c)

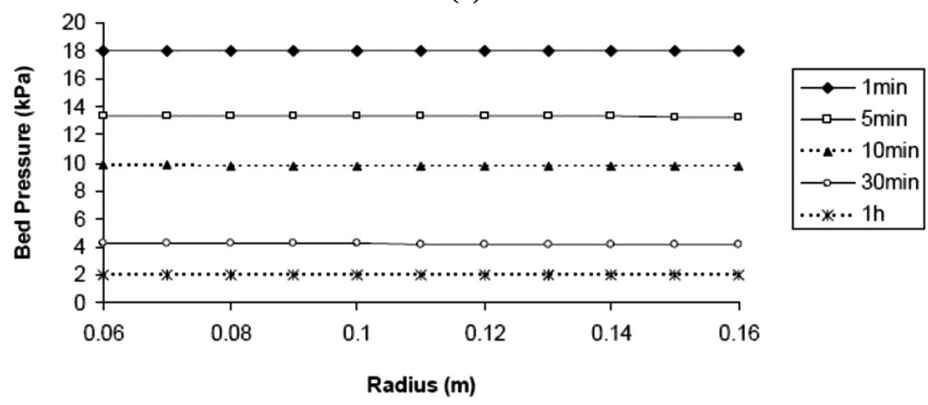

(d)

Figure 6. Change in adsorptive pressure in adsorbent bed; (a) isobaric adsorption, (b) isosteric heating, (c) isobaric desorption, (d) isosteric cooling.

during isobaric adsorption and desorption processes. The bed pressure increased to $20 \mathrm{kPa}$ during the isosteric heating process and decreased to $2 \mathrm{kPa}$ during isosteric cooling. As previously mentioned, the durations of isosteric heating and cooling 


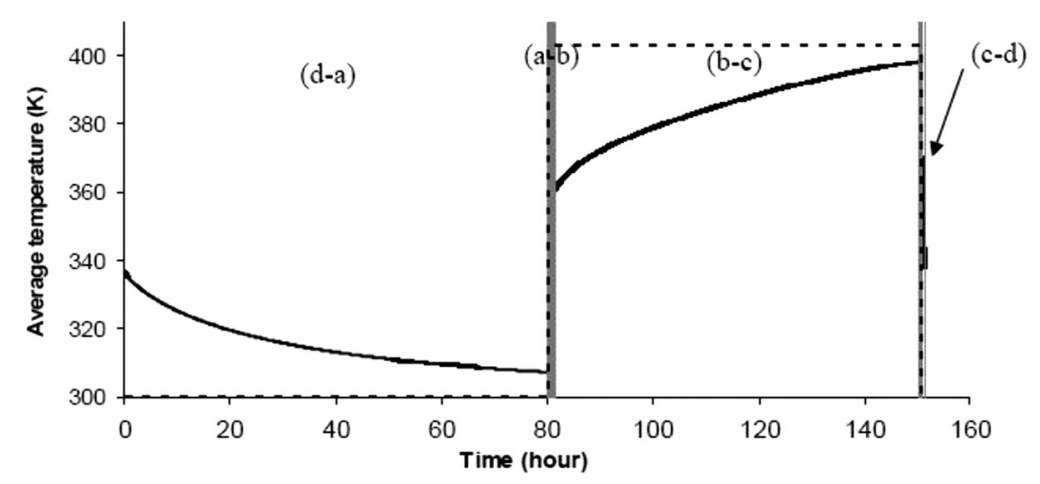

Figure 7. Variation in average temperature of bed throughout the cycle.

processes were relatively short; as a result, changes in the bed pressure during these processes were too steep.

Based on the aforementioned results, high heat transfer resistance caused the propagation of heat in the adsorbent bed to become slower during adsorption and desorption processes. As a result, the duration of the cycle in the adsorbent bed was $150 \mathrm{~h}$. A long adsorption/desorption cycle reduces the cooling power and limits the practical application of the adsorption heat pump. However, the thermal resistance of the bed can be reduced by decreasing the radius of the adsorbent bed. To enhance the thermal conductivity of the bed, the size of the adsorbent particles can also be reduced, which will increase the contact area between granules. Moreover, the use of fin or metal additives can accelerate heat transfer throughout the adsorbent bed (Demir et al., 2010). Alternatively, an increase in $T_{a}$ or a decrease in $T_{c}$ (i.e., a narrower cycle) will reduce the duration of the cycle, which may improve the cooling power. Each aforementioned remedy for the reduction of the duration of the cycle has limitations. Further studies should be performed to achieve the maximum amount of adsorption in a minimum amount of time. The duration of the cycle may be changed from a few seconds for an air-conditioning system to a

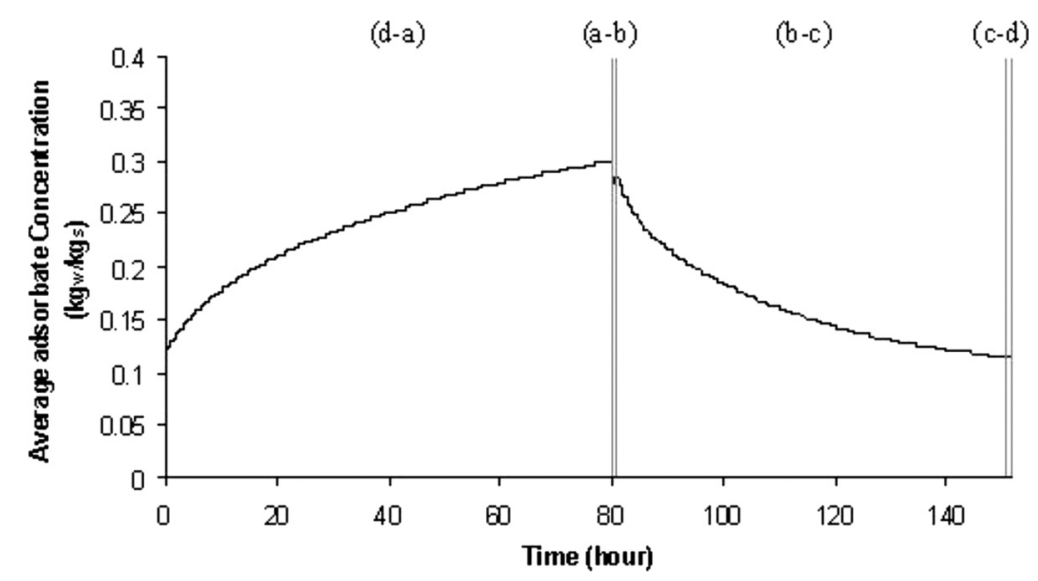

Figure 8. Change in average adsorbate concentration throughout the cycle. 


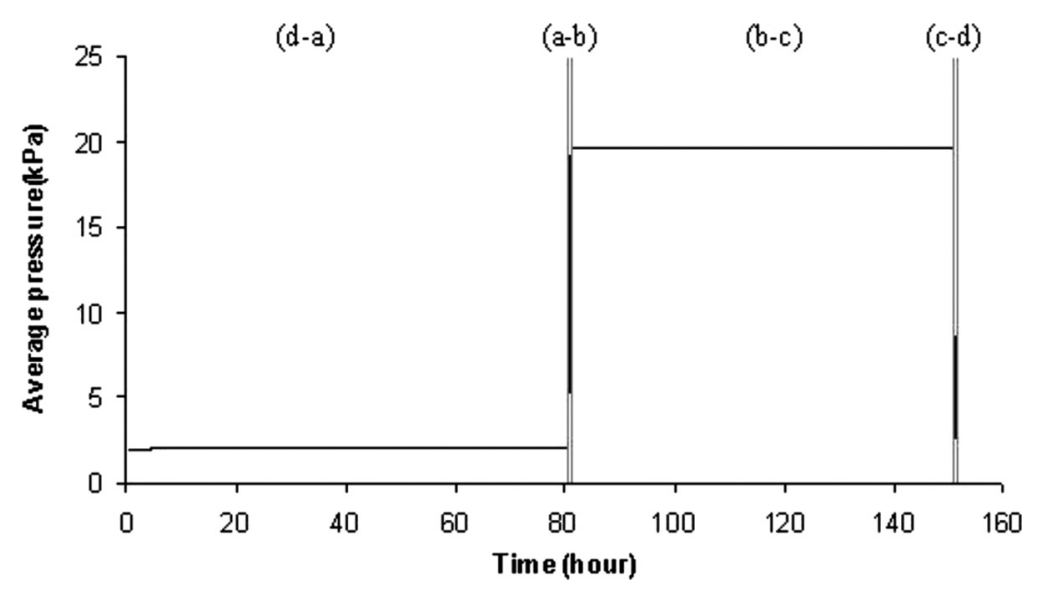

Figure 9. Variation in average pressure of bed throughout the cycle.

day for special industrial processes. Furthermore, the regeneration temperature should not exceed operating temperature of the silica gel recommended by the manufacturer. Moreover, after repetitious adsorption and desorption processes, the regeneration temperature should not affect the adsorption capacity.

\section{Conclusions}

A numerical analysis of heat and mass transfer in an adsorbent bed during an adsorption heat pump cycle, which includes isobaric adsorption, isosteric heating, isobaric desorption, and isosteric cooling, was successfully performed. The duration of the cycle was approximately $152 \mathrm{~h}$ for the simulated annular adsorbent bed. Although the cycle consisted of four processes, adsorption and desorption processes consumed more than $99 \%$ of the cycle period. The duration of the cycle was relatively long because the thermal resistance of the adsorbent bed was large. Due to the porosity of the bed, the adsorptive can flow freely in the voids between particles, and interparticle mass transfer resistance was not a significant factor. The results obtained in this study revealed that the thermal resistance of the bed controls heat and mass transport throughout the bed. A decrease in the thermal resistance of the bed accelerates heat and mass transport during adsorption and desorption processes, reduces the duration of the cycle, and enhances the SCP and SHP of the adsorption heat pump.

\section{Acknowledgment}

The authors would like to thank to the State Planning Organization of Turkey for its great financial support to this project 2003K120690 (DPT-6).

\section{Nomenclature}

$\mathrm{C}_{\mathrm{p}} \quad$ specific heat of adsorbent, $\mathrm{Jkg}^{-1} \mathrm{~K}^{-1}$

$\mathrm{D}_{\text {eff }}$ effective diffusivity, $\mathrm{m}^{2} \mathrm{~s}^{-1}$

$\mathrm{D}_{\mathrm{K}} \quad$ Knudsen diffusivity, $\mathrm{m}^{2} \mathrm{~s}^{-1}$

$\mathrm{D}_{\mathrm{m}} \quad$ molecular diffusivity, $\mathrm{m}^{2} \mathrm{~s}^{-1}$ 
$D_{\text {bed }}$ effective diffusivity of adsorptive in adsorbent bed, $\mathrm{m}^{2} \mathrm{~s}^{-1}$

$\mathrm{D}_{0}$ reference diffusivity, $\mathrm{m}^{2} \mathrm{~s}^{-1}$

E diffusional activation energy, $\mathrm{Jmol}^{-1}$

$\mathrm{K}$ inherent permeability of adsorbent bed, $\mathrm{m}^{2}$

$\mathrm{K}_{\mathrm{app}}$ apparent permeability of adsorbent bed, $\mathrm{m}^{2}$

$\mathrm{M}$ molecular weight of adsorptive, $\mathrm{kg} \mathrm{mol}^{-1}$

$\mathrm{n}$ linear driving force relationship constant

$\mathrm{P}$ pressure, $\mathrm{Pa}$

$\mathrm{R}$ radius of bed, $\mathrm{m}$; ideal gas constant, $\mathrm{J} \mathrm{mol}^{-1} \mathrm{~K}^{-1}$

$R_{p} \quad$ radius of granule, $m$

$r_{p} \quad$ radius of bed pore, $m$

$\mathrm{T}$ temperature, $\mathrm{K}$

$\mathrm{t}$ time, $\mathrm{s}$

$\mathrm{u}$ adsorptive velocity, $\mathrm{m} \mathrm{s}^{-1}$

W average adsorbate concentration, $\mathrm{kg}_{\mathrm{W}} \cdot \mathrm{kg}_{\mathrm{s}}^{-1}$

$\mathrm{W}_{\infty}$ adsorbate concentration in equilibrium, $\mathrm{kg}_{\mathrm{W}} \cdot \mathrm{kg}_{\mathrm{s}}^{-1}$

$\mathrm{W}_{0}$ limiting adsorbate capacity of adsorbent, $\mathrm{kg}_{\mathrm{W}} \cdot \mathrm{kg}_{\mathrm{s}}^{-1}$

\section{Greek Letters}

$\Delta \mathrm{H}_{\mathrm{st}}$ heat of adsorption, $\mathrm{J} \mathrm{kg}^{-1}$

$\Delta \mathrm{t} \quad$ time interval, $\mathrm{s}$

$\varepsilon \quad$ porosity

$\lambda \quad$ thermal conductivity, $\mathrm{W} \mathrm{m}^{-1} \mathrm{~K}^{-1}$

$\mu \quad$ adsorptive viscosity, $\mathrm{Nsm}^{-2}$

$\rho \quad$ density, $\mathrm{kg} \mathrm{m}^{-3}$

$\sigma \quad$ collision diameter for Lennard-Jones potential, $\mathrm{A}^{0}$

$\tau \quad$ tortuosity

$\varphi \quad$ dependent variable

$\Omega \quad$ collision integral

\section{Subscripts}

ads adsorption

app apparent

eff effective

ev evaporation

i inner

init initial

o outer

s adsorbent

sat saturation

$\mathrm{v} \quad$ vapor

w water

$\infty \quad$ equilibrium

\section{References}

Ben Amar, N., Sun, M. L., and Meunier, F. (1996). Numerical analysis of adsorptive temperature wave regenerative heat pump, Appl. Therm. Eng., 16, 405-418.

Bird, B. R., Stewart, E. W., and Lightfoot, N. E. (2002). Transport Phenomena, 2nd ed., 189-191, John Wiley, New York. 
Chahbani, M. H., Labidi, J., and Paris, J. (2002). Effect of mass transfer kinetics on performance of adsorptive heat pump systems, Appl. Therm. Eng., 22, 23-40.

Cho, S.-H., Kim, J.-N., and You, Y.-J. (1992). Silica gel/water adsorption-cooling system, in Proceedings of Solid Sorption Refrigeration Symposium, Paris, November, 18-20.

Chua, T. H., Ng, C. K., Malek, A., Kashiwagi, T., Akisawa, A., and Saha, B. B. (1999). Modeling the performance of two-bed silica gel-water adsorption chiller, Int. J. Refrig., 22, 194-204.

Chua, T. H., Ng, C. K., Wang, W., Yap, C., and Wang, L. X. (2004). Transient modeling of a two bed silica gel-water adsorption chiller, Int. J. Heat Mass Transfer, 47, 659-669.

Cussler, E. L. (1997). Diffusion: Mass Transfer in Fluid Systems, 2nd ed., 104-109, Cambridge Univ. Press, New York.

Demir, H., Mobedi, M., and Ülkü, S. (2008). A review on adsorption heat pump: Problems and solutions, Renew. Sustain. Energy Rev., 12, 2381-2403.

Demir, H., Mobedi, M., and Ülkü, S. (2009). Effects of porosity on heat and mass transfer in a granular adsorbent bed, Int. Commun. Heat Mass Transfer, 36, 372-377.

Demir, H., Mobedi, M., and Ülkü, S. (2010). The use of metal piece additives to enhance heat transfer rate through an unconsolidated adsorbent bed, Int. J. Refrig., 33, 714-720.

De Nevers, N. (1991). Fluid Mechanics for Chemical Engineers, 2d ed., McGraw-Hill, Singapore.

Freni, A., Maggio, G., Vasta, S., Santori, G., Polonara, F., and Restuccia, G. (2008). Optimization of a solar-powered adsorptive ice-maker by a mathematical method, Sol. Energy, 82, 965-976.

Incropera, P. F., and DeWitt, P. D. (1996). Fundamentals of Heat and Mass Transfer, 4th ed., John Wiley, New York.

Kärger, J., and Ruthven, D. M. (1992). Diffusion in Zeolites and Other Microporous Solids, John Wiley, New York.

Leong, K. C., and Liu, Y. (2004). Numerical modeling of combined heat and mass transfer in the adsorbent bed of a zeolite/water cooling system, Appl. Therm. Eng., 24, 2359-2374.

Liu, Y., and Leong, K. C. (2005). The effect of operating conditions on the performance of zeolite/water adsorption cooling systems, Appl. Therm. Eng., 25, 1403-1418.

Liu, Y., and Leong, K. C. (2006). Numerical study of a novel cascading adsorption cycle, Int. J. Refrig., 29, 250-259.

Maggio, G., Gordeeva, L. G., Freni, A., Aristov, Y. I., Santori, G., Polonara, F., and Restuccia, G. (2009). Simulation of a solid sorption ice-maker based on the novel composite sorbent "lithium chloride in silica gel pores," Appl. Therm. Eng., 29, 1714-1720.

Restuccia, G., Freni, A., and Maggio, G. (2002). A zeolite coated bed for air conditioning adsorption systems: Parametric study of heat and mass transfer by dynamic simulation, Appl. Therm. Eng., 22, 619-630.

Restuccia, G., Freni, A., Vasta, S., and Aristov, Y. (2004). Selective water sorbent for solid sorption chiller: Experimental results and modeling, Int. J. Refrig., 27, 284-293.

Sakoda, A., and Suzuki, M. (1986). Simultaneous transport of heat and adsorbate transfer in closed type adsorption cooling system utilizing solar heat, J. Sol. Energy Eng., 108, $239-245$.

Tavman, I. H., and Akinci, H. (2000). Transverse thermal conductivity of fiber reinforced polymer composites, Int. Commun. Heat Mass Transfer, 27, 253-261.

Ülkü, S. (1986). Adsorption heat pumps, J. Heat Recovery Syst., 6(4), 277-284.

Ülkü, S. (1991). Heat and mass transfer in adsorbent beds, in: Convective Heat and Mass Transfer in Porous Media, ed. S. Kakaç, B. Kılkış, A. F. Kulacki, and F. Arınç, 695-724, Kluwer Academic, Boston. 